\title{
Integrated operation of the Beas-Sutlej system
}

\author{
P S RAO* and S RAMASESHAN $\dagger$ \\ *Indian Institute of Management, Bannerghatta Road, Bangalore 560076, India \\ †Civil Engineering Department, Indian Institute of Technology, Kanpur 208 016, India
}

\begin{abstract}
The study deals with the integrated operation of the Beas and Sutlej link, a complex system. It utilizes the methodology developed in an earlier paper for reservoir operation. The results show the definite advantages of conjunctive use and carry over storage. The results also show that it is advantageous to divert as much water from the Beas to the Sutlej as possible.
\end{abstract}

Keywords. Integrated reservoir operation; conjunctive use.

\section{Introduction}

To study the conventional operation of a reservoir system in a multiobjective framework in order to evaluate the trade-offs between irrigation and power implied by past decisions, a case study of the Bhakra reservoir was undertaken. This study demonstrates the methodology and procedures of multi-objective analysis in an integrated framework.

\section{System description}

\subsection{The Beas-Sutlej system}

The Beas river originates in the lower ranges of the Shiwaliks. The catchment area of the river upstream of Pong, where a storage dam has just been completed is $12,561 \mathrm{~km}^{2}$. The average rainfall in the catchment is $1,778 \mathrm{~mm}$. For a mean year the discharge at the Mandi plain varies from 152 cumecs in the dry season to 1,830 cumecs during the monsoon, with an annual average run-off of $16,763 \mathrm{~m} \mathrm{cu} \mathrm{m}$. For a dependable year, the run-off is $12,835 \mathrm{~m} \mathrm{cu} \mathrm{m}$. The Beas joins the Sutlej river at Harike.

The Beas project was undertaken to harness the water and power resources of the Beas river by storage and diversion works. It consists of (i) the Beas-Sutlej link, which comprises a diversion dam at Pandoh across the Beas in the Kulu Valley to transfer $4727 \mathrm{~m}$ cu $\mathrm{m}$ of water to the Bhakra reservoir through tunnels and open conduits capable of passing a maximum discharge of 255 cumecs; and (ii) the Pong dam which provides for a storage dam at Pong with a maximum height of $132.6 \mathrm{~m}$, a gross storage of $8141 \mathrm{~m}$ cu $\mathrm{m}$. and a live storage capacity of $6,767 \mathrm{~m}$ cu $\mathrm{m}$. The power plant will have 4 units with an installed capacity of $60 \mathrm{MW}$ each with provision for two additional units in the future. The water released from the Pong dam and utilized for generation of power will be used for irrigation through the canal system from the Harike headworks. Water from the Ravi is transferred by a diversion at the Madhopur headworks through the Madhopur-Beas link (maximum capacity: 283 cumecs) to the Beas river. This can be 
diverted at Harike to irrigate the Beas command. The Bhakra component of this system has been described in Rao \& Ramaseshan (1985) and the interconnected system of the Beas, the Sutlej and the Ravi is shown in figure 1 of that paper. The inflows of the three rivers for a dependable year are summarized in table 1 and those for a mean year are shown in figure 1.

\subsection{Irrigation and power demands}

A salient feature of the irrigation system is that the releases from the Bhakra reservoir can supply the Sutlej and Beas canal command areas and the releases from the Pong reservoir can be used only in the Beas canal command areas. Gross irrigation requirements for the Sutlej and Beas canals adopted by the Beas Designs Organization (BDO) are given in table 2. A comparison of the irrigation requirements of the Sutlej canal command with those of table 1, Rao \& Ramaseshan (1985) reveals that there has been a slight upward revision of the requirements perhaps due to the increased crop water requirements of the high-yielding varieties.

Constant firm power throughout the year for the Bhakra system was assumed by Minhas et al (1972). Table 3 indicates that planned levels of power generation vary widely between $766 \mathrm{MW}$ from December through April to 1,697 MW in September. It seems that considerable secondary power is generated during the filling season when irrigation requirements are met fully by surface water at a reservoir factor (RF) of 1 . From the available data, three types of firm power distribution over the years are abstracted and used in this study. They are shown in figure 2 . The firm power level from December to April is denoted by $P$, and $\beta_{i}$ is the ratio of the firm power level in any

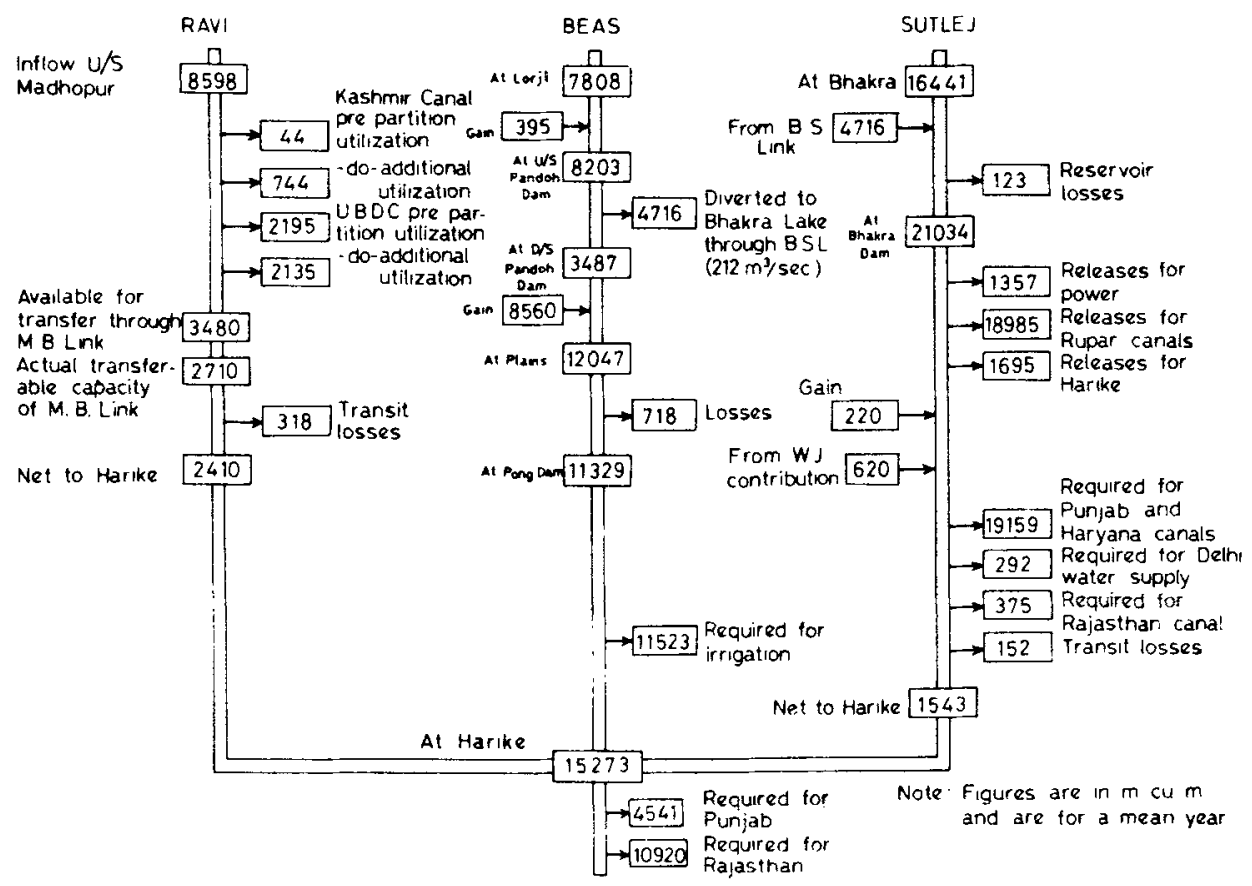

Figure 1. Surface water budget for Punjab water resources system (Lamba \& Prem 1975) 
Table 1. Inflow of rivers Sutlej, Beas and Ravi in cumecs for a dependable year

\begin{tabular}{|c|c|c|c|c|}
\hline Month & $\begin{array}{c}\text { River Sutlej } \\
\text { at Bhakra }\end{array}$ & $\begin{array}{c}\text { River Beas } \\
\text { at Mandi } \\
\text { Plain }\end{array}$ & $\begin{array}{c}\text { River Ravi } \\
\text { at Madhopur }\end{array}$ & $\begin{array}{l}\text { Total } \\
\text { inflow }\end{array}$ \\
\hline June $11-20$ & $707 \cdot 5$ & 360.5 & $312 \cdot 3$ & $1380-3$ \\
\hline $21-30$ & 857.9 & $420-8$ & $327 \cdot 1$ & 1605.8 \\
\hline July & 1233.4 & 918.7 & 513.8 & $2665 \cdot 9$ \\
\hline August & 1293.9 & $1464 \cdot 6$ & 530.6 & $3289 \cdot 1$ \\
\hline Sept $\quad 1-10$ & $821 \cdot 1$ & $944 \cdot 1$ & $317 \cdot 7$ & $2082 \cdot 9$ \\
\hline $11-20$ & $582 \cdot 2$ & 649.9 & $221 \cdot 0$ & $1453 \cdot 1$ \\
\hline $21-30$ & $366 \cdot 1$ & $436 \cdot 8$ & $151 \cdot 7$ & 954.6 \\
\hline October & 233.8 & $256 \cdot 4$ & 95.7 & 585.9 \\
\hline November & 153.8 & $148 \cdot 5$ & 62.9 & $365 \cdot 2$ \\
\hline December & 122.9 & 130.5 & $53 \cdot 0$ & $306 \cdot 4$ \\
\hline January & $109 \cdot 4$ & $125 \cdot 7$ & $55 \cdot 6$ & 290.7 \\
\hline February & $108 \cdot 7$ & $131 \cdot 2$ & 76.8 & 316.7 \\
\hline March & $124 \cdot 2$ & 157.6 & 128.4 & $410 \cdot 2$ \\
\hline April & 162.6 & 193.6 & 195.2 & 551.4 \\
\hline May & $314 \cdot 3$ & $249 \cdot 9$ & $257 \cdot 4$ & 821.6 \\
\hline June $1-10$ & $524 \cdot 3$ & 272.5 & $295 \cdot 1$ & $1086 \cdot 9$ \\
\hline $\begin{array}{l}\text { Total inflow } \\
\text { tare metres }\end{array}$ & $1 \cdot 3723$ & $1 \cdot 2835$ & 0.6713 & $3 \cdot 3271$ \\
\hline
\end{tabular}

(Bhalla \& Bansal 1975).

Table 2. Irrigation requirements for Sutlej and Beas canal systems in cumecs

\begin{tabular}{|c|c|c|c|}
\hline Month & $\begin{array}{l}\text { Sutlej canal } \\
\text { system at } \\
\text { Ropar }\end{array}$ & $\begin{array}{c}\text { Beas canal } \\
\text { system at } \\
\text { Harike }\end{array}$ & $\begin{array}{l}\text { Tatal of Sutlej } \\
\text { and Beas } \\
\text { canal systems }\end{array}$ \\
\hline 1 & 2 & 3 & 4 \\
\hline April & $388 \cdot 3$ & 262.5 & 650.8 \\
\hline May & $760-9$ & $406 \cdot 1$ & 1167.0 \\
\hline June $\quad 1-10$ & $773 \cdot 2$ & $620-6$ & $1393 \cdot 8$ \\
\hline $11-30$ & $773 \cdot 2$ & $628 \cdot 3$ & $1401 \cdot 5$ \\
\hline July & $658 \cdot 0$ & 570.5 & $1228 \cdot 5$ \\
\hline August & $658 \cdot 0$ & $570-5$ & $1228 \cdot 5$ \\
\hline Sept. $1-10$ & 770.8 & $623 \cdot 2$ & $1394 \cdot 0$ \\
\hline $11-20$ & $770-8$ & $683 \cdot 3$ & $1454 \cdot 1$ \\
\hline $21-30$ & 770.8 & 803.5 & $1574 \cdot 3$ \\
\hline Oct. $\quad 1-15$ & $776 \cdot 7$ & 713.6 & $1490 \cdot 3$ \\
\hline $16-31$ & 776.7 & 602.9 & $1379 \cdot 6$ \\
\hline November & 703.6 & $492 \cdot 2$ & 1195.8 \\
\hline December $\quad 1-10$ & 675.8 & 381.5 & $1057 \cdot 3$ \\
\hline $11-31$ & $392 \cdot 3$ & 328.6 & 715.9 \\
\hline Jan. $1-15$ & 388.9 & 317.6 & $706 \cdot 5$ \\
\hline $16-31$ & 395.6 & 317.6 & $713 \cdot 2$ \\
\hline Feb. $\quad 1-10$ & 409.8 & 338.6 & $748 \cdot 4$ \\
\hline $11-28$ & $582 \cdot 8$ & 374.8 & 957.6 \\
\hline March & $589 \cdot 0$ & $519 \cdot 9$ & 1108.9 \\
\hline
\end{tabular}

(Bhalla \& Bansal 1975) 


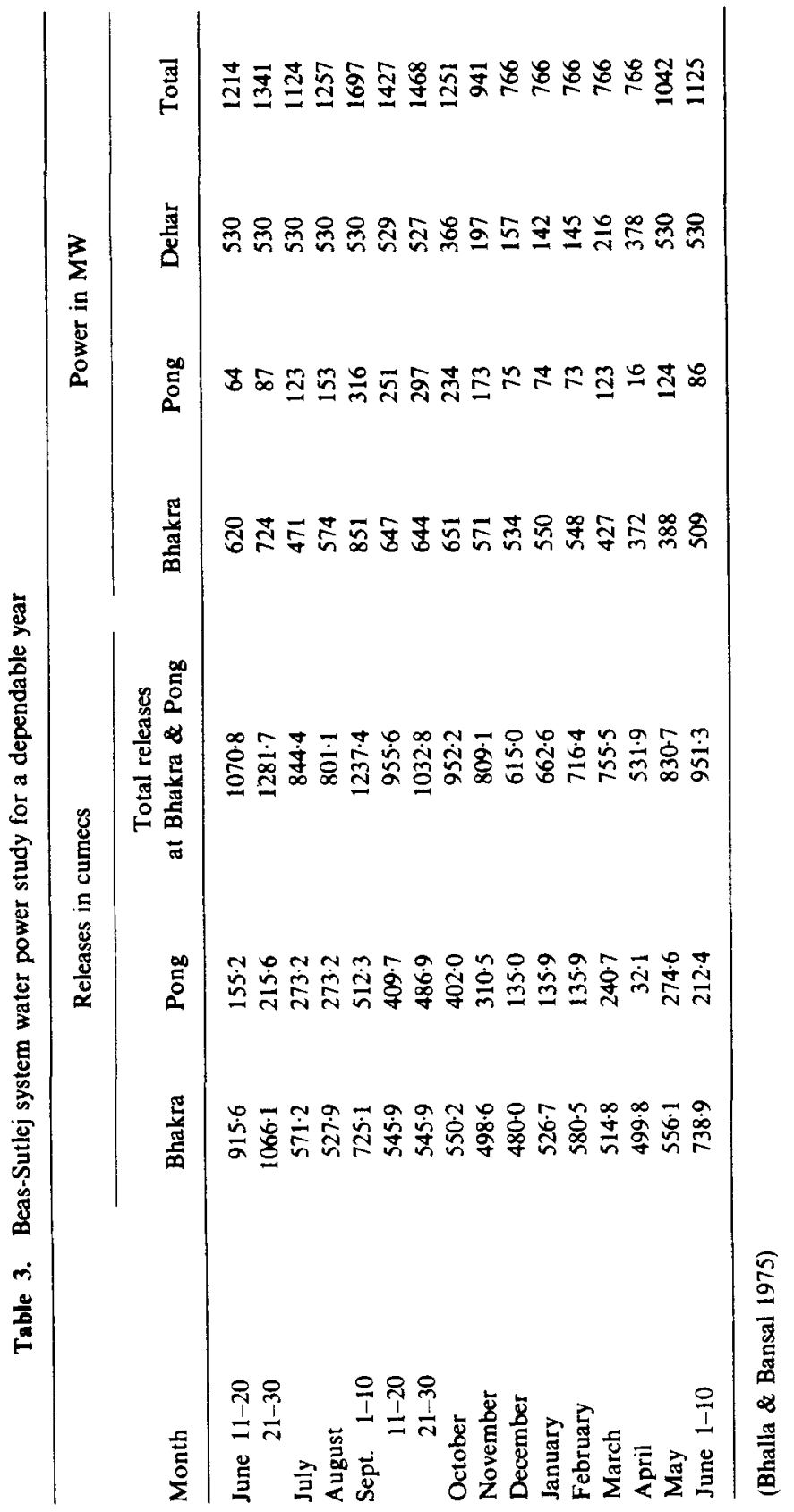



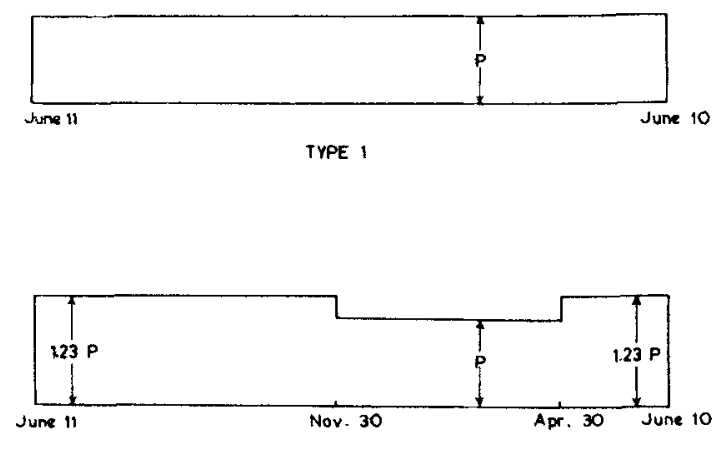

TYPE 2

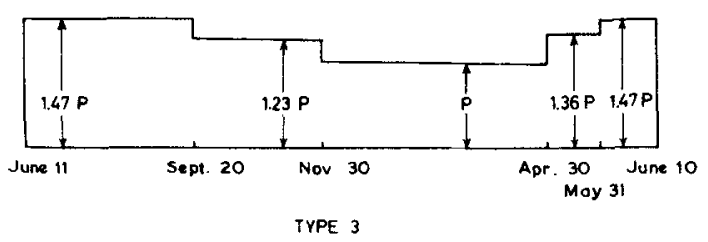

Figure 2. Firm power distributions

month $i$ to $P$. A uniform firm power level, i.e. $\beta_{i}=1$ for all $i$, is assumed in type 1 , while in type $2, \beta_{i}=1$ from December to April and $\beta_{i}=1.23$ for other months. Similarly in type 3 , values of $i$ vary in different months from 1 to 1.47 .

\subsection{Planned operating policies}

The planned operation of the reservoirs of the interconnected Beas-Sutlej system is described by Bhalla \& Bansal (1975) and Lamba \& Prem (1975). The operating policy of the system of reservoirs is the same as that of the Bhakra reservoir $(\$ 2.4$, Rao \& Ramaseshan 1985). In the original Beas project report, the Bhakra and Pong reservoirs were assumed to be depleted almost simultaneously to their dead pond levels, the firm power being $766 \mathrm{MW}$. Releases from the two reservoirs and power generation during different months of the year are given in tables 2 and 3. Bhalla \& Bansal suggested staggering the time of depletion of the Bhakra and Pong reservoirs to their respective dead pond levels and thus increasing the firm power from 766 to $799 \mathrm{MW}$. Planning by BDO is confined to the management of the surface waters. Conjunctive utilization of surface and ground waters has not been considered by them.

\section{Conjunctive utilization}

\subsection{System model}

Conjunctive utilization models are developed for integrated management of surface and ground waters. They are necessarily simplified representations of a more complex reality, as in the planning studies of BDO, and are limited to the use of published information. The aim is essentially to focus on the methodology and demonstrate the utility of model building and systems studies for improvement. 
The system is shown in figure 3. A linear programming model of the system is developed and used in these studies. The model maximizes the level of firm power $P$. Irrigation demands are to be satisfied in each of the subperiods. The power required to lift groundwater is over and above the firm power that is to be supplied. The mathematical formulation of the model is as follows:

Objective function: Maximize $P$

\subsection{Constraints}

3.2a Power constraint: The power generated in the system in any period should be equal to or greater than the firm power demand plus the power required to lift groundwater in the Bhakra and Beas irrigation commands. The model assumes that dump power has no value and is indifferent to whether this constraint is defined as an equality or inequality. In this study, power constraints are equality constraints.

$$
\begin{aligned}
& K_{1 i} T_{1 i}+K_{2 i} T_{2 i}+K_{3} D I_{i}-n_{i} \beta_{i} P-P_{1 i}-P_{2 i} \geqslant 0, \\
& \text { with } \quad i=1,2, \ldots, 16 .
\end{aligned}
$$

where the first subscripts $1,2 \& 3$ refer to the Bhakra, Pong and Dehar plants respectively; the second subscript $i$ indicates the variable in a subperiod $i$; coefficients $K_{1 i}, K_{2 i}$ and $K_{3}$ are the power conversion factors (or energy rate functions) for power plants and represent power generated by a unit volume of water in megawatts per cumec and $K_{3}$ is a constant for all the subperiods; $T_{1 i}, T_{2 i}$ are the flows through the turbines at the power plants; $D I$ is the inflow diverted through the Beas-Sutlej link and passing through the Dehar power plant in cumec days; $n_{i}$ is the number of days; and $P_{1 i}$ and $P_{2 i}$ are power in megawatt days used for lifting groundwater in the Bhakra and Beas command areas respectively.

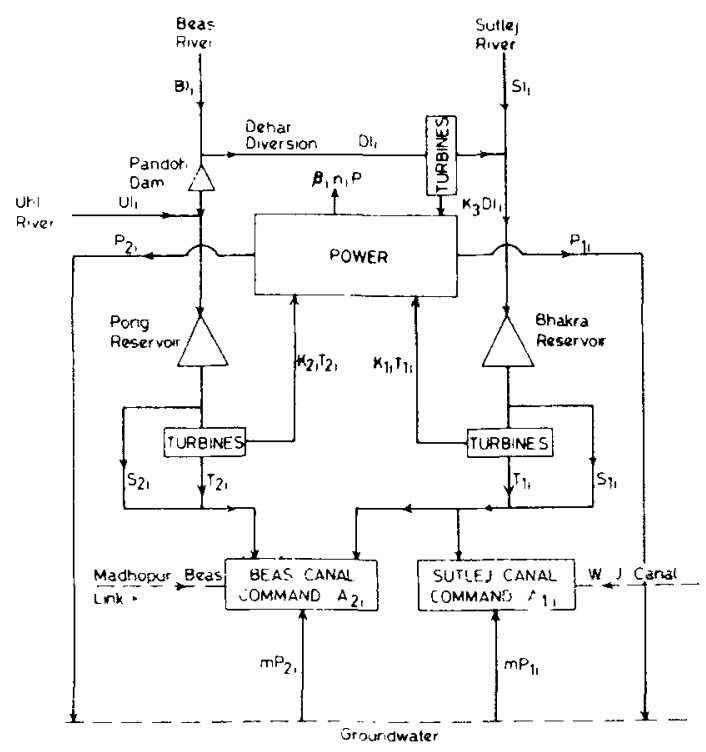

Figure 3. The Beas-Sutlej system model 
3.2b Turbine capacity—inflow constraints: Flows through turbines are limited by the maximum turbine flow capacities in any of the periods. Diversion through Dehar is, in addition, limited by the upstream Beas flows. Hence, the flow through turbines at the Dehar plant is the minimum of the available flow for diversion and the turbine flow capacity.

$$
\begin{aligned}
& T_{1 i} \leqslant T C_{1 i}, \\
& T_{2 i} \leqslant T C_{2 i}, \\
& D I_{i} \leqslant \operatorname{Min}\left(\mathrm{BI}_{i}, \mathrm{DTI}_{i}\right),
\end{aligned}
$$

where $T C_{1 i}, T C_{2 i}$, and $D T I_{i}$ are the maximum turbine flow capacities; $B I_{i}$ is the inflow in the Beas river above Pandoh and $i$ varies from 1 to 16 . The flow unit used in this study is cumec day.

3.2c Irrigation constraints for the Beas and Sutlej canal systems: The total irrigation requirements of the Beas and Sutlej canal systems should be met by (i) releases at the Bhakra reservoir through the turbines and/or outside the turbines; (ii) releases at the Pong reservoir through the turbines and/or outside the turbines; and (iii) groundwater which may be used in either the Beas or the Sutlej command areas or in both.

$$
\begin{aligned}
& \left(T_{1 i}+S_{1 i}\right)+\left(T_{2 i}+S_{2 i}\right)+m\left(P_{1 i}+P_{2 i}\right) \geqslant A_{1 i}+A_{2 i} \\
& \text { with } \quad i=1,2, \ldots, 16,
\end{aligned}
$$

where $S_{1 i}$ and $S_{2 i}$ are flows released through irrigation sluices or over the spillway and not through turbines; $m$ is the volume of groundwater lifted by unit power (cumecs/MW) and $A_{1 i}$ and $A_{2 i}$ are the irrigation requirements of the Sutlej canal system at Ropar and of the Beas canal system at Harike respectively.

The irrigation requirements of the Sutlej canal system should be met by (i) releases at the Bhakra reservoir through the turbines and/or outside the turbines; and (ii) groundwater lifted in the Bhakra command area

$$
\begin{aligned}
& \left(T_{1 i}+S_{1 i}\right)+m \cdot P_{1 i} \geqslant A_{1 i} \\
& \text { with } i=1,2, \ldots, 16
\end{aligned}
$$

$3.2 \mathrm{~d}$ Continuity and capacity constraints: The continuity equation relates the volume of storage at the end of any period to the initial volume, inflows and releases. The capacity constraint equations limit the volume of storage to the reservoir capacities and these are used for the filling periods. In the depletion period, a simpler relationship, viz the sum of the releases during the total depletion period, limited to the total utilizable storage in the reservoir at the end of the filling period plus the inflows during the depletion period, is used.

\section{Bhakra reservoir:}

(i) Filling period

$$
\begin{aligned}
& T_{1 i}+S_{1 i}-D I_{i}+V_{1, i}-V_{1, i-1}=S I_{i} \\
& \text { and } V_{1, i} \leqslant C_{1} \text { with } i=1,2, \ldots, 6
\end{aligned}
$$


(ii) Depletion period

$$
\sum_{i=7}^{16}\left(T_{1 i}+S_{1 i}-D I_{i}\right)-V_{1,6}+V_{1,0}=\sum_{i=7}^{16} S I_{i}
$$

Pong reservoir:

(i) Filling period

$$
\begin{aligned}
& T_{2 i}+S_{2 i}+D I_{i}+V_{2, i}-V_{2, i-1}=B I_{i}+U I_{i} \\
& \text { and } V_{2, i} \leqslant C_{2} \text { with } i=1,2, \ldots, 6 .
\end{aligned}
$$

(ii) Depletion period

$$
\sum_{i=7}^{16}\left(T_{2 i}+S_{2 i}+D I_{i}\right)-V_{2,6}+V_{2,0}=\sum_{i=7}^{16}\left(B I_{i}+U I_{i}\right)
$$

where $V_{1}, V_{2}$ are the volumes of storage; $C_{1}$ and $C_{2}$ are the reservoir capacities; and $S I$ and $U I$ are the inflows in the Sutlej river and in the Uhl river which joins the Beas river at Mandi; the unit is cumec day for all variables.

\subsection{Data and assumptions}

3.3a Number of subperiods: As in the BDo studies, the year is divided into sixteen subperiods, six in the filling period and ten in the depletion period.

3.3b Power conversion factors: The power conversion factors $\left(K_{1 i}, K_{2 i}\right.$, and $\left.K_{3}\right)$ are calculated for each reservoir for each subperiod from the BDo data in table 3 and are shown in table 4. As in the study on the Bhakra reservoir (Rao \& Ramaseshan 1985) their variation as a function of the actual reservoir level in each subperiod is ignored. Dehar is a constant head power plant and the power conversion factor is computed as $2.616 \mathrm{MW} /$ cumec from the total power generated and the total flow through the plant in a year.

3.3c Irrigation requirements: The irrigation requirement of the Sutlej canal system to be supplied from the Bhakra reservoir in any subperiod is taken as the minimum of the Sutlej canal requirement (table 2) and the Bhakra reservoir release (table 3 ). The total irrigation requirements for the system are available from the BDO study. Both are shown in table 4. With contributions from other sources, namely, the Western Jamuna canal and the Madhopur-Beas link, accounted for, they correspond to a filling period RF of about 1 and a depletion period RF of about 0.85 .

3.3d Turbine capacities: Assuming a standby unit of $120 \mathrm{MW}$ and a maximum power plant capacity of $930 \mathrm{MW}$ at Bhakra, and a standby of $60 \mathrm{MW}$ and a maximum power plant capacity of $300 \mathrm{MW}$ at Pong and using the power conversion factors, the maximum turbine flow capacities are calculated (table 4). The Beas river flow available for diversion at Pandoh is calculated from the Beas river flow at Mandi in proportion to the ratio of the respective catchment areas.

3.3e Volume of storage in reservoirs: A summary of river inflows and reservoir releases in the filling and depletion periods for a dependable year is shown in figure 4 . The storage capacities of Bhakra and Pong reservoirs are respectively 9,320 and $6,767 \mathrm{mcum}$. The storage capacities in the BDo study in a dependable year are 


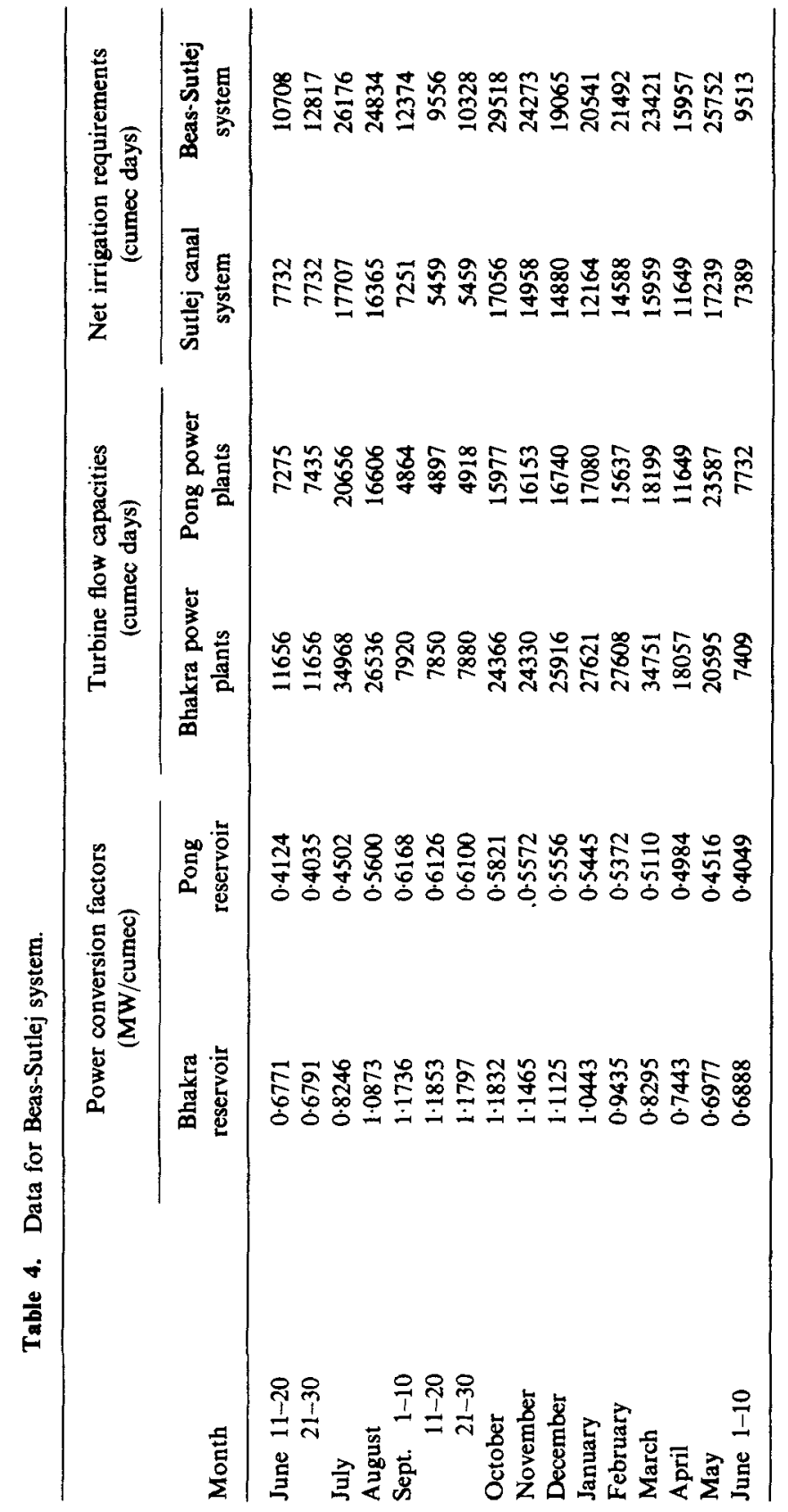




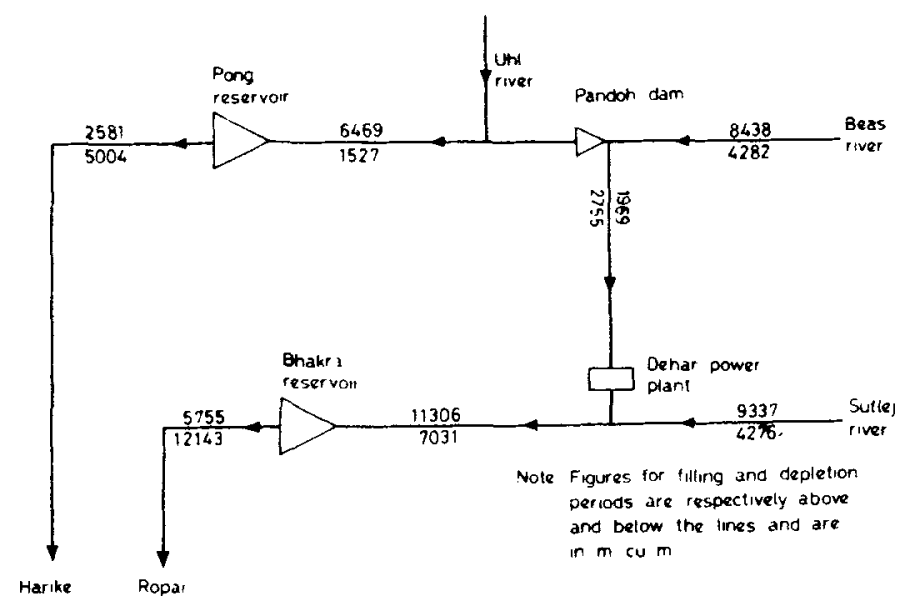

Figure 4. Water balance of the Beas-Sutlej system

respectively 5,112 and $3,477 \mathrm{~m}$ cu $\mathrm{m}$ corresponding to final volumes of storage at the end of the depletion period, 4,208 and $3,290 \mathrm{~m} \mathrm{cu}$ m respectively. These are assumed to be the levels of storage at the beginning of the filling period (case 1) and are referred to as initial volumes in this study. In case 6 the initial volumes of storage are $2,426 \mathrm{~m} \mathrm{cu} \mathrm{m}$ in Bhakra corresponding to a dead storage level of $445.62 \mathrm{~m}$, and zero in Pong. Cases 2 to 5 correspond to intermediate values and details are given in table 5 .

3.3f Power for groundwater: It is assumed that $1 \mathrm{MW}$ of power can lift 2.832 cumecs of groundwater. This corresponds to a lift of $25 \mathrm{~m}$ and for Punjab this is a conservative assumption (Minhas et al 1972).

3.3g Dehar diversion flows: The system is studied with two different assumptions regarding the Beas-Sutlej diversion flows.

Model 1: For comparability of results, Dehar inflows are calculated from the seasonal distribution of power generation and total diversion as specified by the BDO study (Mehndiratta \& Hoon 1973; Bhalla \& Bansal 1975). It is assumed in this model that they are prespecified and are not subject to control. Model 1 has 109 variables and 106 constraints.

Model 2: It is assumed that the Beas-Sutlej diversions can be changed, if necessary, subject to the availability of flows in the Beas above Pandoh for diversion and limited by the turbine flow capacity at Dehar. Additional diversion of water through Dehar generates power at Dehar and Bhakra at heads higher than at Pong and can also meet irrigation demands in the Bhakra or Beas canal systems. This flexibility can and does increase the firm power level. Model 2 has 125 variables and 122 constraints.

\section{Discussion of results}

The firm power level is maximized for each case defining initial reservoir volumes for each type of firm power distribution and for specified (model 1) and variable (model 2) Dehar diversions. MPsX (Mathematical Programming System Extended) available in the Harvard-MIT Computer system was used and each solution required about 45 to 50 seconds for computation and execution. The maximum firm power levels for all the cases are shown in table 5 . 


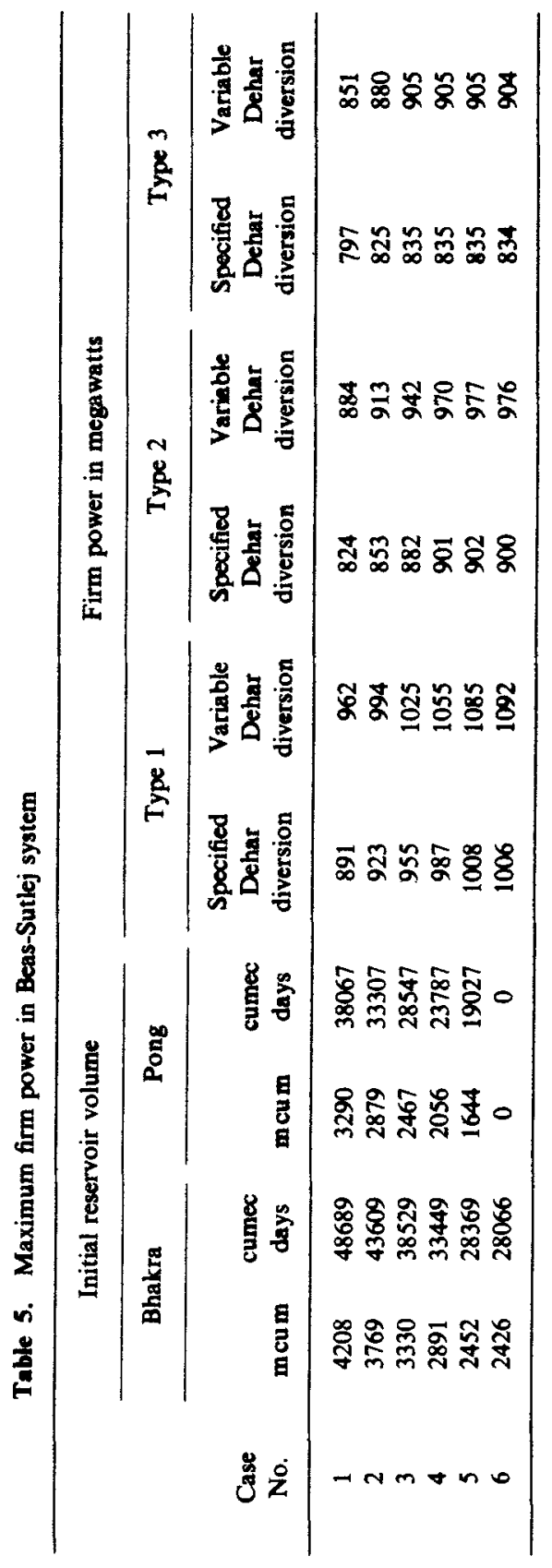


For any level of initial storage, the firm power level for type 1 distribution is higher than that for type 2 , which in turn is higher than that for type 3 . This implies that higher values of variable $\beta_{i}$ reduce the firm power level.

Even in case 1 with wasteful spillage of the order of $10 \%$ of total storage, the firm power is 797, 824 and $891 \mathrm{MW}$ respectively for firm power distribution types 3,2 and 1. With no spillage, the firm power increases respectively to 835,902 and $1008 \mathrm{MW}$. Thus conjunctive utilization can increase firm power at least by $36 \mathrm{MW}$ above that of improved operation and $69 \mathrm{MW}$ above the original planned operation of BDO. In case firm power distribution can be represented by type 1 or type 2, the firm power levels increase further by $173 \mathrm{MW}$ and $67 \mathrm{MW}$ aboye those of type 3. The small differences between case 5 and case 6 seem to be due to numerical errors.

Since in this study the power conversion factors are considered to be independent of the variations of the actual reservoir level in any period, the variation between case 1 and case 6 corresponds to various levels of spillages. Variable Dehar diversion (model 2) increases firm power levels over specified Dehar diversion (model 1) by $54 \mathrm{MW}$ to $86 \mathrm{MW}$ or 7 to $8 \%$.

The details of power generation and of groundwater utilization are not reported in the study but are summarised below:

(i) Generally, in June and July, the Pong reservoir is filling up and no releases are made; and for a continuous period of two to three months between November and February also, no releases are made from Pong.

(ii) Whenever possible, water is diverted through Dehar as the power generation at Dehar and Bhakra is much larger than that at Pong.

(iii) The current practice is to release surface water liberally in the filling period to meet the irrigation demand and use groundwater essentially in the depletion period. However, the results of this study are contrary to the current practice and they indicate groundwater use generally between May and November and not from December to April. Groundwater utilization peaks in September, is significant for parts of July, August and October, and is somewhat smaller in May, June and November. The quantities vary from solution to solution. For example, the groundwater used for case 1 , type 1 of model 1 varies as follows: 36,298 and 438 cumecs in the three subperiods of June: 236 cumecs in July; 226 cumecs in August; 500, 286 and 110 cumecs in the three subperiods of September; and 193 cumecs in November. A maximum pumping capacity of 500 cumecs is indicated and in case the pumps operate only for part of the day and not fully, the installed capacity should be proportionately higher. By staggering the cropping pattern, the peak groundwater use may be reduced resulting in a higher utilization of the installed pumping capacity.

In the Kharif season, irrigation demands are high and constraining and a large amount of secondary or dump power is currently generated. By lifting groundwater in this period, it is possible to conserve surface water for future use and to eliminate any secondary power generation except when unavoidable. The surface water so conserved is generally adequate to meet the full irrigation demands in the Rabi season except perhaps for very limited groundwater use in one or two periods. In addition to this, the firm power level is also raised significantly i.e., part of the seasonal excess power of low value is converted to firm power of high value. This is similar to the concept of using a pumped storage scheme. But rather than looking for a smaller reservoir at a higher elevation, the larger and lower ground-water reservoir is used advantageously. It may 
still be possible to generate dump power using the wasteful spills provided both reservoirs can be full at the end of the filling period.

\section{Trade-off analysis}

The operation of the Beas-Sutlej system with a specified irrigation demand was considered in the study discussed above. The advantages of conjunctive utilization with variable Dehar diversion flows (model 2) have also been demonstrated. Model 2 is used here to study the trade-off between irrigation and power in the integrated operation of the surface and groundwater system. The three types of firm power distributions considered earlier are also used here. Initial volumes of storage in the reservoirs are assumed at dead storage levels and these correspond to case 6 of table 5 . In order to study the implication of dry year flows on systems operation, the study is repeated for type 2 firm power distribution only with dry year flows.

\subsection{Data and assumptions}

The data used in this study are the same as in the study discussed in $\S 3$. For any RF the irrigation demands for the Bhakra and Bhakra-Beas commands are calculated from the canal requirements in table 2. Subtracting the contributions from other sources (the Madhopur-Beas link and the Western Jamuna canal), the corresponding net irrigation releases required for the RF are determined. 1965-66 is the driest year on record (as of 1969) for inflows to the Bhakra reservoir. Beas river inflows at Dehar and estimates of inflows to the Pong reservoir were derived for the same year and used for the study with dry year flows.

\subsection{Discussion of results}

The maximum firm power was determined for $R F$ levels of $0.6,0.75,0.85,0.9,0.95$ and 1 . All the three types of firm power distributions (figure 2) were considered for dependable year inflows and only type 2 distribution for the dry years. The results are presented in table 6 and figure 5. The original and improved planned operations of BDO are also indicated in the same figure. For any RF, the firm power for type 1 distribution is larger than that for type 2 distribution, which in turn is larger than that for type 3 distribution. This is similar to the results for planned operation with an RF of 1 in the filling period and 0.85 in the depletion period (table 5).

Table 6. Maximum firm power for different reservoir factors

\begin{tabular}{lcccc}
\hline & \multicolumn{4}{c}{ Firm power in megawatts. } \\
\cline { 2 - 5 } $\begin{array}{l}\text { Reservoir } \\
\text { factor }\end{array}$ & $\begin{array}{c}\text { Type 1 } \\
\text { Dependable year }\end{array}$ & $\begin{array}{c}\text { Type 2 } \\
\text { Dependable year }\end{array}$ & Dry year & $\begin{array}{c}\text { Type 3 } \\
\text { Dependable year }\end{array}$ \\
\hline 0.60 & 1129 & 1000 & 815 & 923 \\
0.75 & 1121 & 995 & 803 & 918 \\
0.85 & 1107 & 987 & 789 & 912 \\
0.90 & 1098 & 980 & 780 & 906 \\
0.95 & 1089 & 972 & 770 & 900 \\
1.00 & 1079 & 962 & 758 & 890 \\
\hline
\end{tabular}




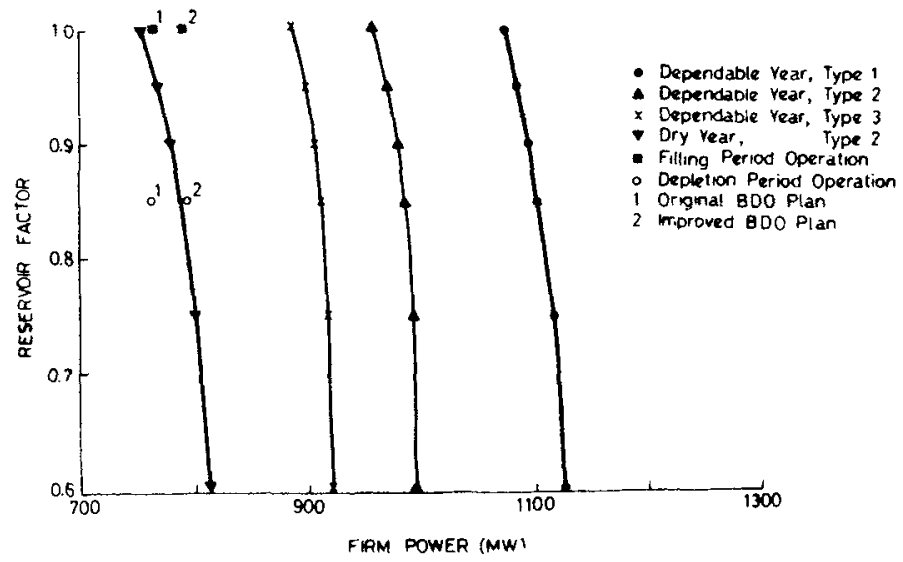

Figure 5. Transformation curves for the Beas-Sutlej system

For a dependable year, the points of operation according to the original and improved plans of the BDO lie very much within the transformation curves. Conjunctive utilization, integrated operation and optimization increase the firm power level of the improved BDO operation ( $799 \mathrm{MW}$ ) by at least 91,163 and $280 \mathrm{MW}$ respectively for type 3, type 2 and type 1 distributions. Even in a dry year the original planned levels of power and irrigation can be met by adopting conjunctive utilization in an integrated framework.

The trade-off between irrigation and power ranges between 140 and $200 \mathrm{MW} / \mathrm{RF}$. The trade-off between irrigation and power implied in the planned operation of the Bhakra reservoir in an average year is between 240 and $260 \mathrm{MW} / \mathrm{RF}$ (table 14, Rao \& Ramaseshan, 1985). At higher firm power levels, the relative value of power may decrease indicating a higher trade-off. As the operation at RF of 1 implies a trade-off of utmost $200 \mathrm{MW} / \mathrm{RF}$, operation at RF of at least 1 is indicated. An increase in RF level from 0.85 to 1 can be achieved at a loss in firm power of 22 to $28 \mathrm{MW}$ in a dependable year, and $31 \mathrm{MW}$ in a dry year. This corresponds to a loss of $2.5 \%$ to $4 \%$ of firm power for a gain in irrigation of $17.5 \%$. Hence it is necessary and possible to meet the irrigation requirements fully, viz at $\mathrm{RF}$ of 1 throughout the year.

The firm power level reached in a dry year is $200 \mathrm{MW}$ (i.e. $20 \%$ ) less than that reached in a dependable year. It shows that wide fluctuations in firm power levels are inherent in the system due to hydrologic uncertainty and they remain wide even with conjunctive utilization. This emphasizes the need for over-the-year carryover from wet years to dry years.

\section{Conclusions}

The following conclusions are derived from this study.

(i) System modelling and optimization of conjunctive utilization of surface and ground waters in an integrated framework leads to a better understanding of the interactions between the irrigation and firm power objectives;

(ii) It is advantageous to divert as much water as possible from the Beas to the Sutlej through the Dehar power plant. This generates much more power at Dehar and Bhakra than at Pong; 
(iii) Contrary to current practice groundwater should be used from May to November and surface water conserved in reservoirs during the period. This raises the firm power level significantly;

(iv) The levels of irrigation and power planned for a dependable year from the reservoirs of the Beas-Sutlej system can be attained even in a dry year by conjunctive utilization of surface and groundwaters;

(v) It is desirable and certainly possible to meet the full irrigation requirements of the system throughout the year; and

(vi) Over-the-year carryover storage from wet years to dry years is essential to reduce the wide fluctuations in the levels of objectives attained in different years.

\section{References}

Bhalla B S, Bansal R N 1975 J. Central Bd Irrigation Power 32: 15

Lamba S S, Prem K S 1975 Integrated development of rivers Sutlej, Beas and Ravi for optimum utility of water in north-western area of India; Presented at the IWRA II World Congress on Water Resources, New Delhi, Reprint, Vol. 3; p. 79

Mehndiratta K R, Hoon R N 1973 J. Central Bd Irrigation Power 30: 349

Minhas B S, Parikh K S, Srinivasan, T N 1972 Sankya, Indian J. Stat. B34: 105

Rao P S, Kamaseshan S 1985 Sadhana 8: 179-206 